\title{
Papaya (Carica papaya) Classification by Software
}

\author{
Juliana Aparecida Fracarolli, Inácio Maria Dal Fabbro and Ingrid Nehmi de Oliveira \\ School of Agricultural Engineering, University of Campinas, Campinas, SP 13083-875, Brazil
}

\begin{abstract}
In this paper, it suggested the selection of papayas by image processing employing low-cost equipment for data acquisition. This may allow the process automation selection and classification of agricultural products for small farmers or small traders. The objective of this work was to evaluate two papaya varieties ("Solo" and "Formosa”) using image programs for selection of miscellaneous format detection and fruit mapping coloration. The experiment occurred at an optic laboratory and it used a diffused light, camera, computer and papaya fruits, and for image processing, the ImageJ software, in addition to computer programs that have been developed for image processing. The detection of varied sizes and the fruit classification by mapping color were conducted using the software. The program for evaluating the two varieties format worked with $100 \%$ of the fruits and the one for mapping coloration with $80 \%$ correct results. These results showed that the program had low error and could be used for fruit selection.
\end{abstract}

Key words: Fruit classification, image processing, machine vision, quality.

\section{Introduction}

During ontogeny, the papaya fruits undergo important changes in their characteristics. It is possible to quantify these changes as maturity indicator to help identify at what level it is. Researchers used several traditional fruit indicators for it, such as total soluble solids (TSS) ( ${ }^{\circ}$ Brix), firmness, titratable acidity (TA) and ratio [1]. The feature that influences the consumer's judgment most as to the degree of maturation is the color of the skin, because it represents the relationship between maturity, physical and chemical changes [2].

The coloring of fruit and vegetables is related to the amount of the pigments, chlorophyll and carotenoids, present in chloroplasts and chromoplasts and phenolic compounds in the vacuoles [3]. In Fig. 1, it is possible to see the difference in the peel color from green to ripe fruit.

Balbino [4] classified the papaya ripening stages, according to the percentage of yellow color in the skin of fruit according to Table 1 . The process is also used for pineapples to associate the color with increased TSS and the decrease in TA, analyzing varieties of the

Corresponding author: Juliana Aparecida Fracarolli, professor, research field: post-harvest technology. yellow of the coloration of the skin $[5,6]$.

The organoleptic quality of the fruit depends on growth conditions, harvest time, while providing a level of ripeness and post-harvest handling. When harvesting the fruit before its full physiological maturity, the maturation of the fruit process is impaired and its quality is affected [7]. The harvesting of ripe fruit completely reduces the shelf-life, creates difficulty in handling and transportation, due to the low mechanical strength, and leads to damage losses [8].

The maturation process of papaya is completed from 4-6 months after the flower opening [9]. Normally, for marketing reasons, the point for harvesting is when they have streaks or bands with a $50 \%$ yellow peel [10]. Papayas destined for export are harvested when the peel color changes from a dark green to a light green tone, the pulp color becomes pink and the seeds are black. The end consumer generally prefers fruit with yellow peel or bright orange flesh and dark orange pulp [11, 12].

A technique is destructive when performed after cutting the fruit or vegetable or even when it is performed after the disintegration of the plant tissues. In such cases, the samples cannot be reused. There are techniques for nondestructive evaluation of the fruit 

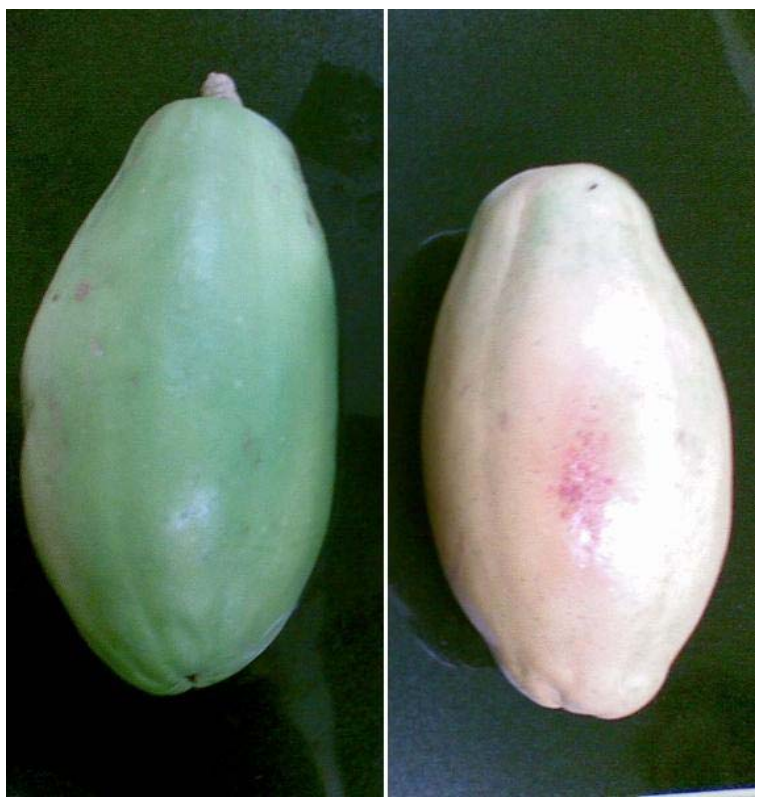

Fig. 1 Peel color of unripe and ripe papaya.

maturity parameter based on the International Commission on Illumination (CIE) color [13], analysis of the normalized difference vegetation index (NDVI) [14], spectroscopy remission visible/near-infrared (VIS/NIR), and analysis of the chlorophyll fluorescence emission $[15,16]$. All these approaches have been used nondestructively to assess the ripening of fruit and changes in the chlorophyll content [17].

CIE proposed the CIE $L^{*} a^{*} b^{*}$ or CIELAB, color scale in 1976 [8]. This is a standardization to facilitate comparisons between various uses and colors. The CIELAB color scale is approximately uniform. In a uniform scale, the differences between points in the color space correspond to visual differences between colors. The CIELAB color space is organized in a cubic shape. The $U$ axis is vertical. The maximum value of $L$ is 100 , which is a perfect diffuse reflection, and it is white. The minimum value of $L$ is zero and it is black. The $a$ and $b$ axes present numerical limits. Positive values on the $a$ axis represent shades of red, while negative values on the $a$ axis represent shades of green. Positive values on the $b$ axis represent in yellow, and blue represents negative values. Fig. 2 showed the color space CIELAB [18].

The color is subjective and people interpret colors differently. Thus, the peel or pulp color may be measured instrumentally, using colorimeters or spectrophotometers. Colorimeters standardize the observer and the light source. The use of colorimeters to measure the color of agricultural products is very common, and it is an easy and objective way to interpret the results [19].

The evaluation of the physiological maturity of fruit can be used by producers, technicians or workers who perform quality control. It is important that they can be performed in the field simply. It is also important that objective analyses, as opposed to subjective ones, are made (through measurement), and also that they are not destructive [3]. So the objective of this work was to evaluate two papaya varieties ("Solo" and “Formosa”) using image programs for selection of miscellaneous format detection and fruit mapping coloration.

\section{Materials and Methods}

Both studies were conducted at the optic laboratory of the School of Agricultural Engineering of the University of Campinas (FEAGRI/UNICAMP). The experiments evaluated two varieties of papayas, "Solo"

Table 1 Classification of the ripening stages of papaya according to skin color.

\begin{tabular}{lll}
\hline Stage of maturity & Classification & Description \\
\hline Subgroup 0 & Unripe & Grown and fully-developed fruits with 100\% green peel \\
Subgroup 1 & Maturing & Beginning of the change of skin color with a 15\% yellowed peel \\
Subgroup 2 & 1/4 maturing & Fruits with up to $25 \%$ of the surface of the skin yellow \\
Subgroup 3 & $1 / 2$ maturing & Fruits with up to $50 \%$ of the surface of the skin yellow \\
Subgroup 4 & 3/4 maturing & Fruits with 50\%-75\% of the surface of the skin yellow \\
Subgroup 5 & Ripe & Fruit with 76\%-100\% of the surface of the skin yellow and appropriate for consumption \\
\hline
\end{tabular}

Source: $[4,20]$. 


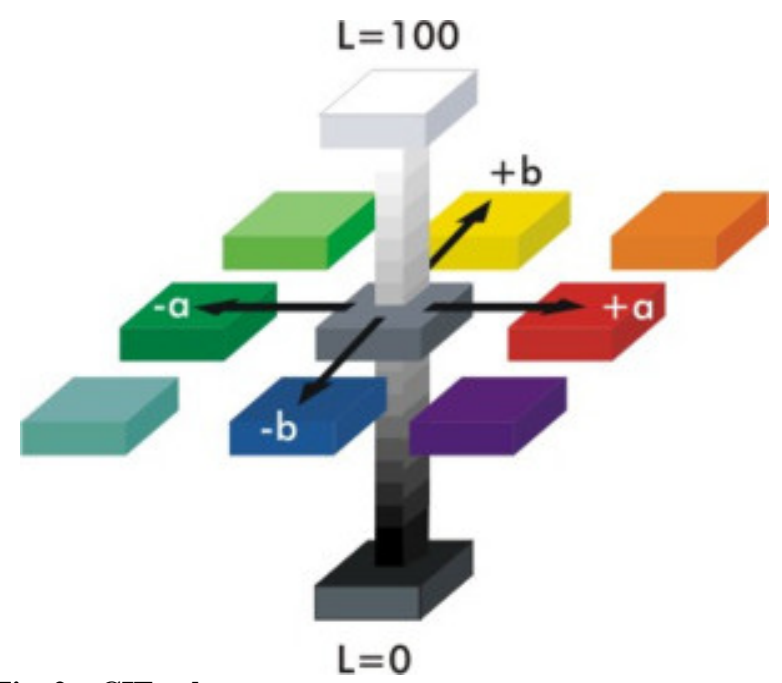

Fig. 2 CIE color space.

Source: [18].

and "Formosa", both common in the Brazilian market. The first experiment was to detect the variety of the papaya using an algorithm to analyze the format, and the second to evaluate maturity using the color of the papaya.

\subsection{Detection of Miscellaneous Fruit Shape}

There were three repetitions for the "Formosa" variety and four for "Solo", they were arranged with a black bottom, for better contrast, in a random placement. A SAMSUNG ${ }^{\circledR}$ model SC-HMX20C took different pictures of the fruits using natural light at a vertical distance of $1 \mathrm{~m}$. Fig. 3 showed one of the pictures taken.
The first step processing the images using the ImageJ [21] program was the threshold (Fig. 4). After that, occurred the binarization of the image that separated a part from the rest, in this case, the fruits were separated from the bottom (Fig. 5).

For selection, the algorithm compared the Feret diameter, which was a measurement of the perpendicular distance between the tangents that touched the opposite parallel sides of the profile. Using the Feret diameter for the fruits, they were classified as belonging to the "Formosa" variety, when the difference in the linear length of the fruit compared to the average fruit length has a $20 \%$ increase [20]. For the computer program, the classification as variety "Formosa" occurred when Feret diameter was greater than 300 pixels; if lower, the program was classified as "Solo".

\subsection{Mapping the Peel Coloration}

For evaluating the peel coloration, the variety used was "Solo". Twenty fruits selected from the local market in five different stages of maturation were used, and they were sorted according to the Brazilian standards for papaya specifications (Fig. 6) [20].

The procedure is, for each image, duplication and decomposition of the colors (the decomposition of the colors was done in one of the two images, after

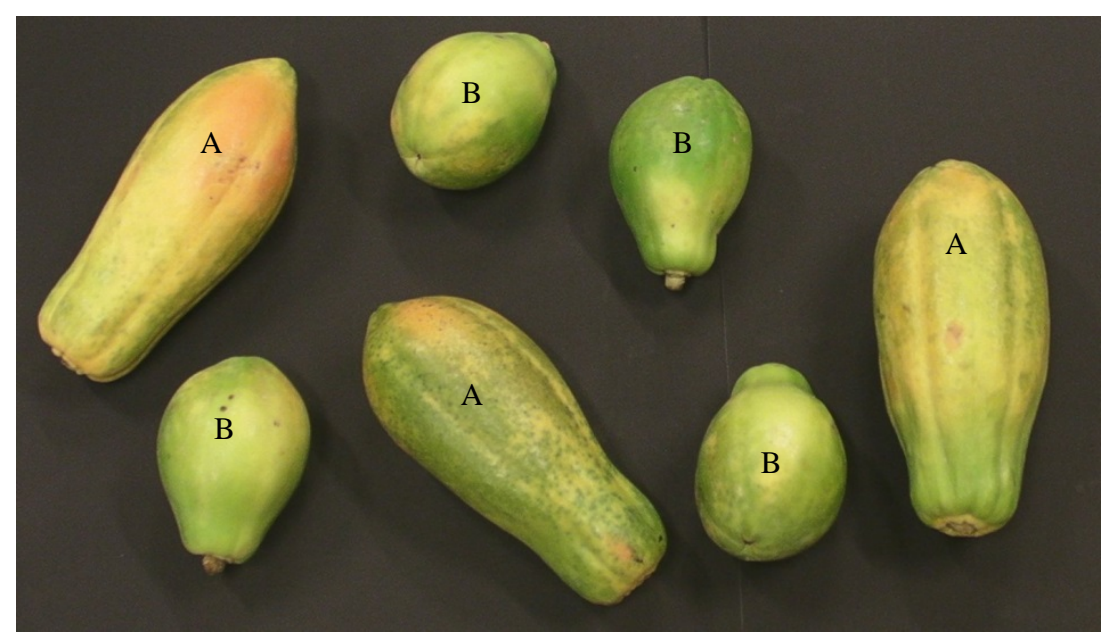

Fig. 3 “Formosa" (A) and "Solo" (B) papaya varieties used in the experiment. 


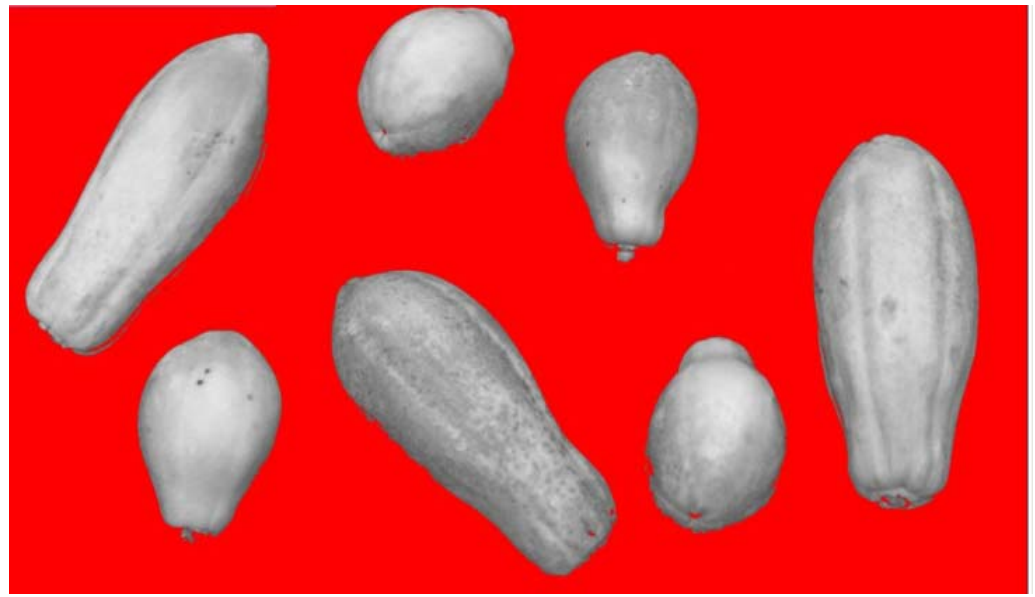

Fig. 4 Stage of the image processing-threshold.
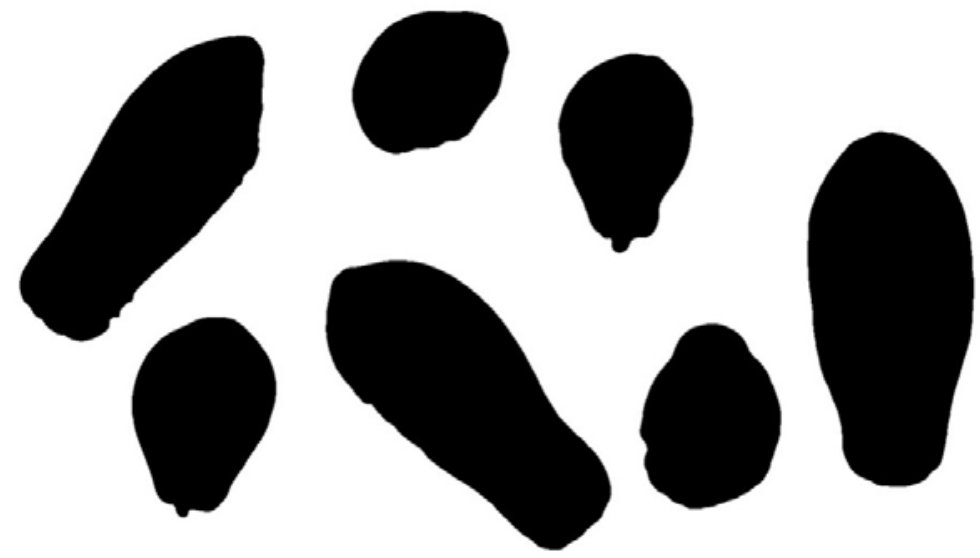

Fig. 5 Stage of the image processing - binarization.

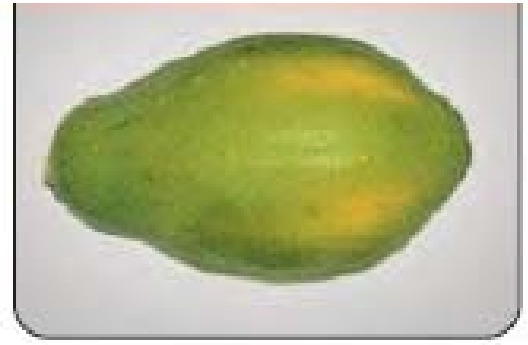

(a)

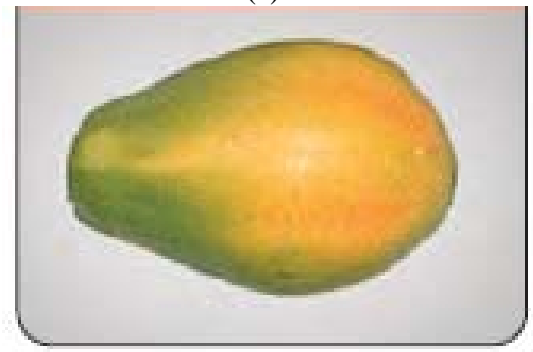

(d)

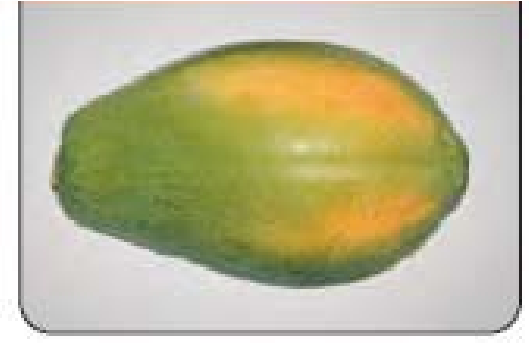

(b)

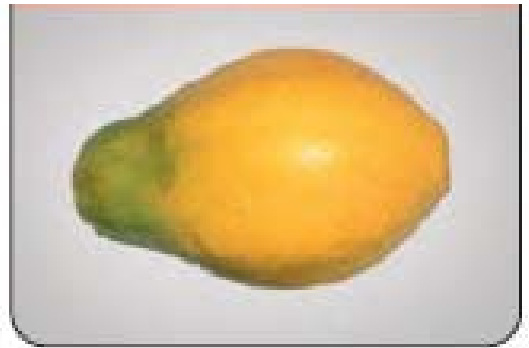

(e)

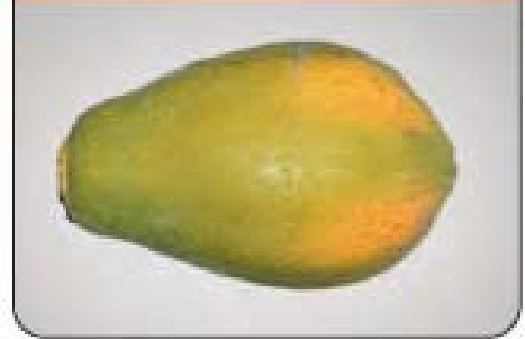

(c)

Fig. 6 Fruit ripening (a), 1/4 mature fruit (b), 1/2 mature fruit (c), 3/4 mature fruit (d) and ripe fruit (e). Source: [20]. 
duplication. The other initial image was used for mapping the coloration.) in the RGB channels, and then selecting the green channel. With the binarized image, the analysis of the particles conducted was possible to obtain the coordinates. Then the region of interest (ROI) was defined as an ellipse, 25\% lower than the coordinates of the fruit, and was used for color analysis (Fig. 7).

With the ROI, it was possible to conduct the color histogram. The value of the gray level of the red channel was obtained for each image, which was the color differential in relation to mature papayas. The color profile for papayas at three different stages of maturation was obtained (Fig. 8).

According to the value of the gray level of the red channel, a subgroup classification of papayas was allocated by the program using the conditionals "if", "else if" and "else".

For statistical analysis of the data, a Tukey test at 5\% probability was performed for the gray level variable in the red channel for fourth repetitions of each subgroup of classification of the images.

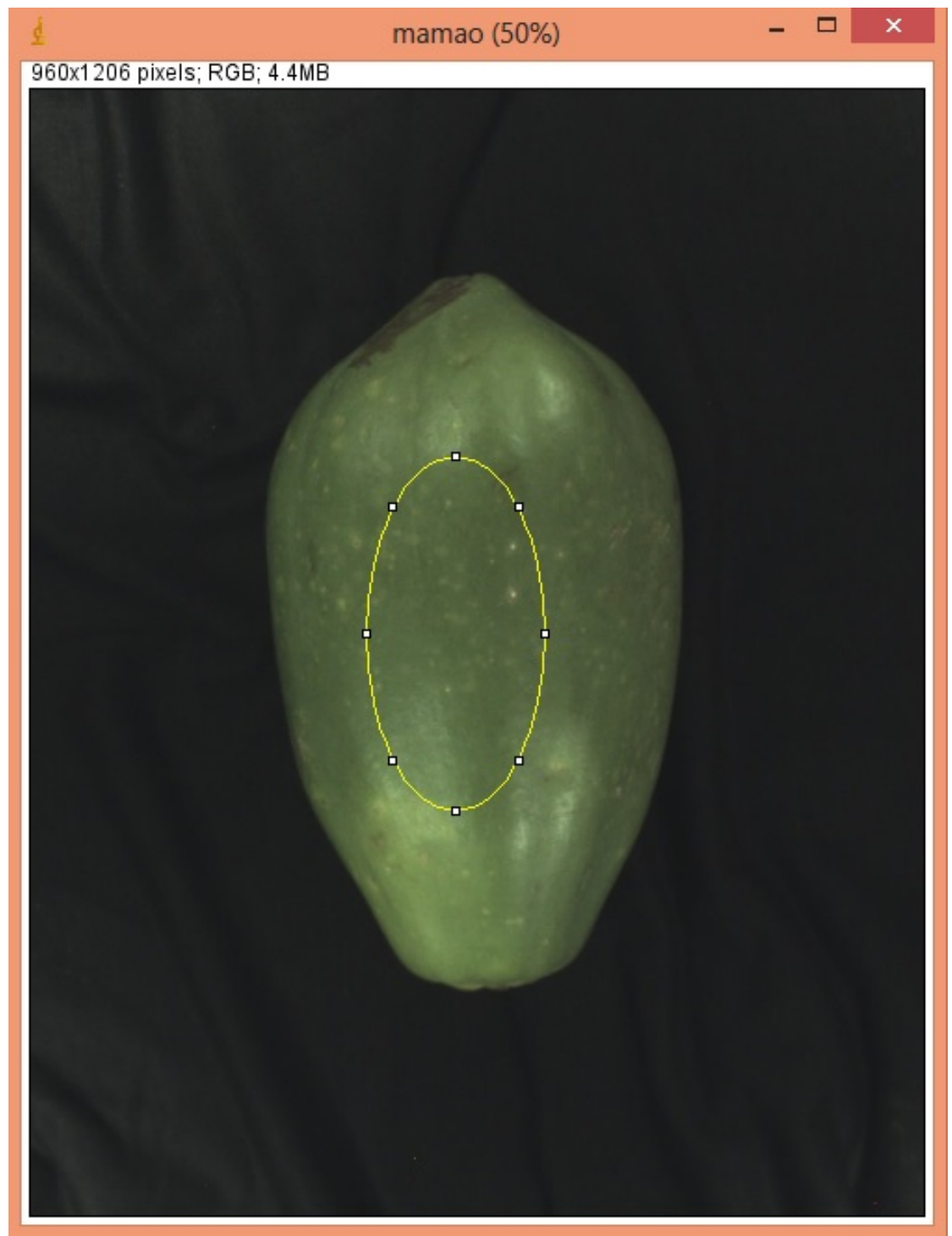

Fig. 7 ROI in papayas. 


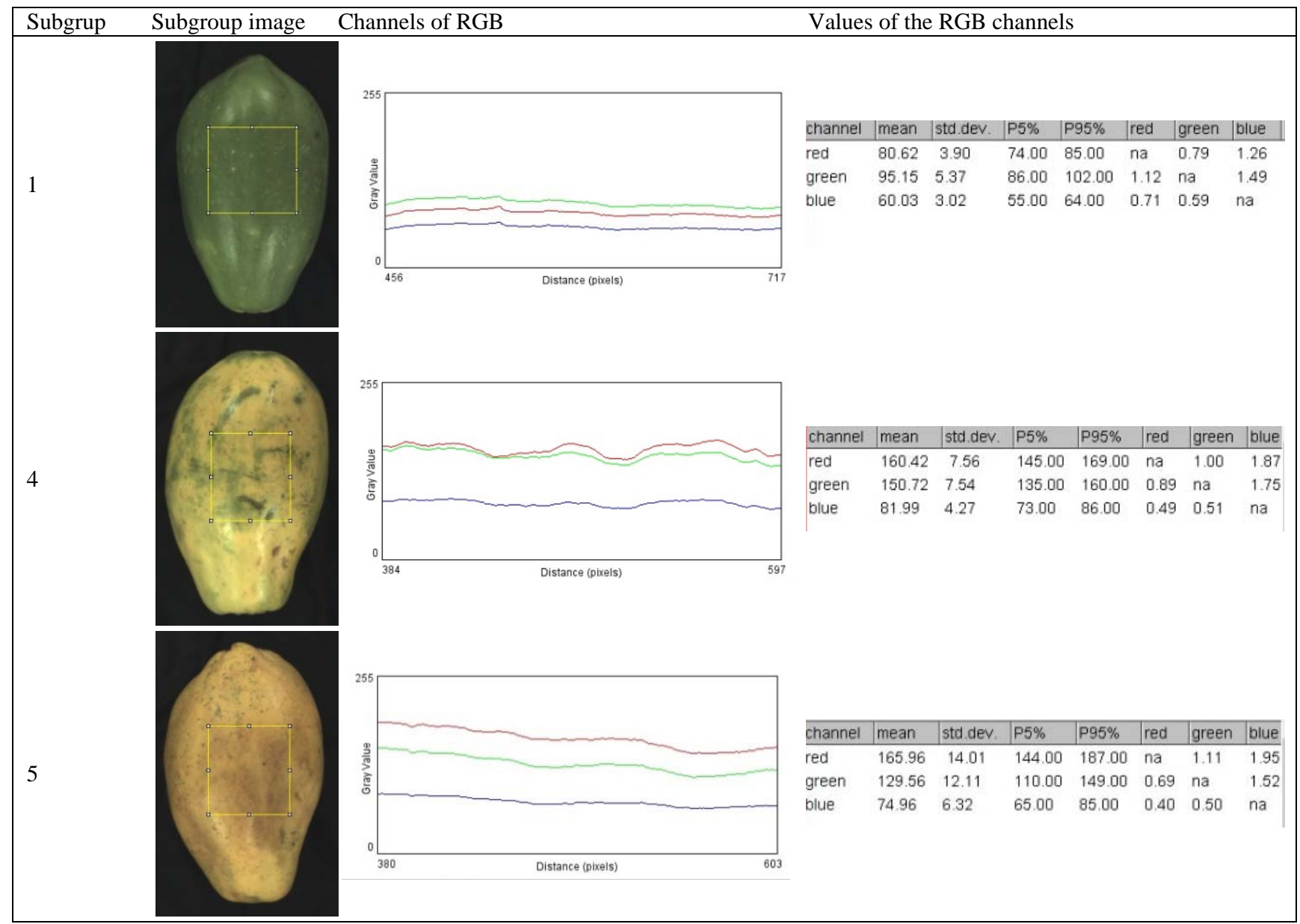

Fig. 8 Region selected for color profile with values for the RGB channels for fruits in different subgroups.

Source: Compiled by the author.

\section{Results and Discussion}

\subsection{Detection of Miscellaneous Shapes}

After the threshold and binarization, the resulted image was processed by the algorithm for evaluation of the papayas variety. The first image generated by the program is an identification of each object found and numbered (Fig. 9). The number identified was used for further spreadsheet of identification.

The program resulted for the papaya image a correct separation of the objects analyzed and correct drawing of the shapes, showing an initial good evaluation (Table 2). Errors identifying objects or shapes can cause errors in the algorithm variety detection.

The area, perimeter, circularity, Feret diameter and the strength of each one of the fruits were identified and the classification of fruits using the software was possible, as shown in Fig. 10, and referred to the numbered fruits in Fig. 9.

The study of the varieties of fruits can also lead to their selection by size or volume by processing images, such as oranges [22]. Fruit selection, using nondestructive methods for both producers and markets, can be useful, because in one program it is possible to evaluate different types of selection with low cost of acquisition.

The program had all the classifications right according to market classification, as shown in Table 1 . So the program is working with satisfactory response and error.

\subsection{Mapping Coloration}

The second part of the experiment was the 
classification of the papayas by color. Fig. 11 showed the images used in the program. It showed different maturity levels of papayas of the variety "Solo". The images are shown from less maturity (image 000) to mature (image 019).

From the images 001-004, it was possible to see that the papayas are in major in a green color, showing that they were not ready to be consumed. In images 005-008, the fruits were a little yellowish, a point where was possible to be found on markets. Images
009-012 were the ideal point of maturity for consumption and market. In images 015-019, the fruits were very mature, at the point of consumption.

In Fig. 5, notice that images 000, 001, 002 and 004 were classified as subgroup 1 , which corresponded to fruit ripening with the first yellow signs not exceeding to more than $15 \%$ of the peel. Image 003 was classified as subgroup 2, which corresponded to a $1 / 4$ ripe fruit with $15 \%-25 \%$ of yellow peel surface.

The papayas in the images are all green, which
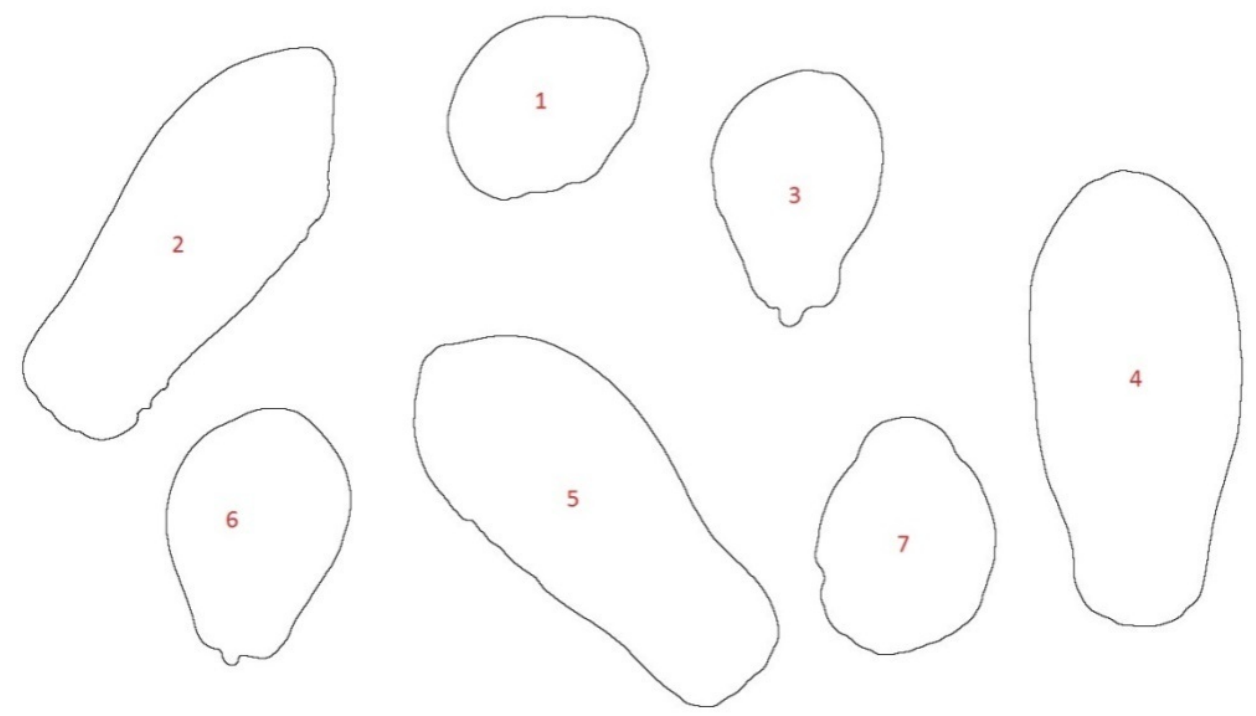

Fig. 9 Results obtained by the program (numbers used to identify the objects).

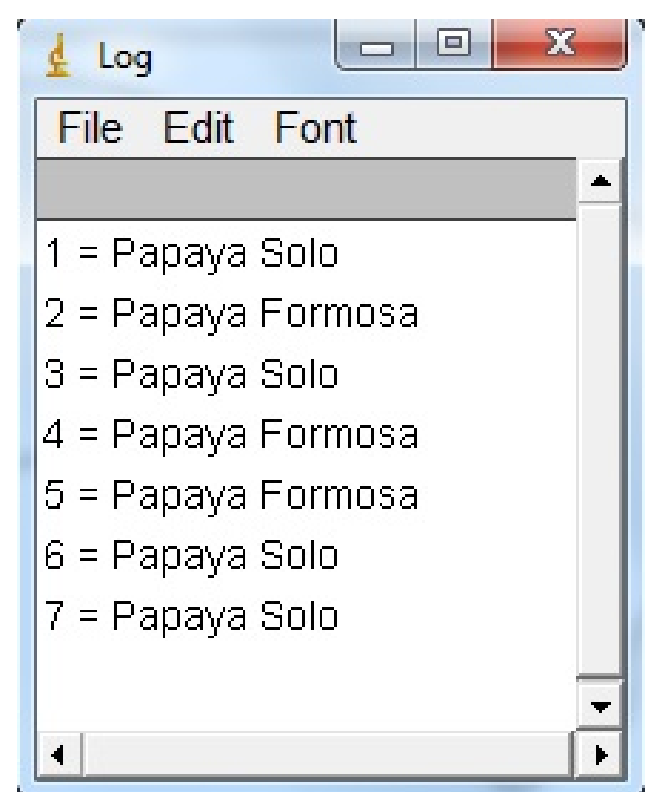

Fig. 10 Output window of the program for fruit classification.
Table 2 Analysis of classification of papayas in market classification vs. program classification.

\begin{tabular}{lll}
\hline & Market classification & Program classification \\
\hline 1 & Solo & Solo \\
2 & Formosa & Formosa \\
3 & Solo & Solo \\
4 & Formosa & Formosa \\
5 & Formosa & Formosa \\
6 & Solo & Solo \\
7 & Solo & Solo \\
\hline
\end{tabular}

corresponds to the subgroups 1 and 2. Images 006, 007, 008 and 017 were classified in subgroup 3, corresponding to ripe fruit with $25 \%-50 \%$ of yellow peel surface. Except for image 017, the images are according to subgroup description.

Images 005, 009, 010, 014, 015 and 019 were in subgroup 4, which corresponded to 3/4 ripe fruits, that 


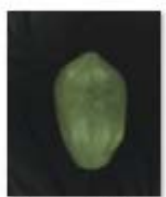

Image000.jpg

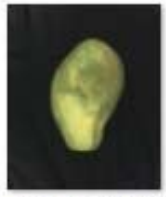

Image005.jpg

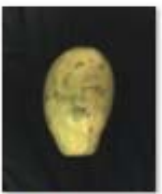

Image010.jpg

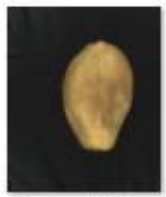

Image015.jpg

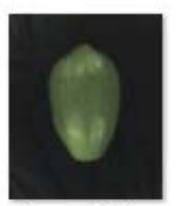

Image001.jpg

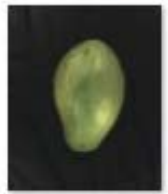

Image006.jpg

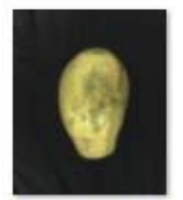

Image011.jpg

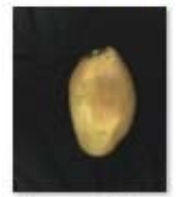

Image016.jpg

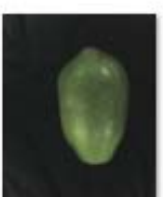

Image002.jpg
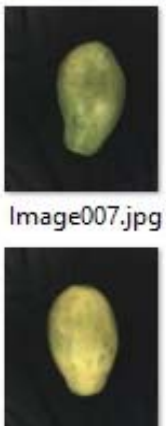

Image012.jpg

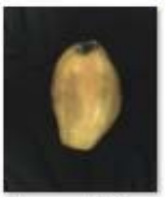

Image017.jpg

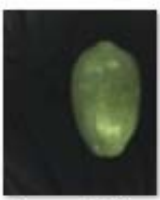

Image003.jpg

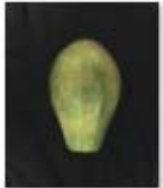

Image008.jpg

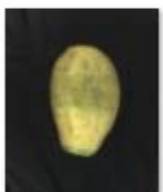

Image013.jpg

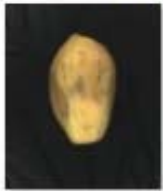

Image018.jpg

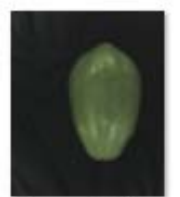

Image004.jpg

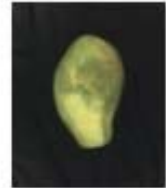

Image009.jpg

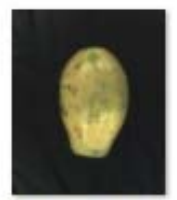

Image014.jpg

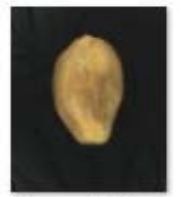

Image019.jpg

Fig. 11 Images processed for the classification of papayas.

\begin{tabular}{|c|c|c|}
\hline \multicolumn{2}{|c|}{ d Papaya Classification } & \multirow[b]{3}{*}{$\boldsymbol{\Delta}$} \\
\hline \multicolumn{2}{|c|}{ File Edit Font } & \\
\hline Name & Color & \\
\hline Image000.jpg & Subgroup 1 & \\
\hline Image001.jpg & Subgroup 1 & \\
\hline Image002.jpg & Subgroup 1 & \\
\hline Image003.jpg & Subgroup 2 & \\
\hline Image004.jpg & Subgroup 1 & \\
\hline Image005.jpg & Subgroup 4 & \\
\hline Image006.jpg & Subgroup 3 & \\
\hline Image007.jpg & Subgroup 3 & \\
\hline Image008.jpg & Subgroup 3 & \\
\hline Image009.jpg & Subgroup 4 & \\
\hline Image010.jpg & Subgroup 4 & \\
\hline Image011.jpg & Subgroup 5 & \\
\hline Image012.jpg & Subgroup 5 & \\
\hline Image013.jpg & Subgroup 5 & \\
\hline Image014.jpg & Subgroup 4 & \\
\hline Image015.jpg & Subgroup 4 & \\
\hline Image016.jpg & Subgroup 5 & \\
\hline Image017.jpg & Subgroup 3 & \\
\hline Image018.jpg & Subgroup 5 & \\
\hline Image019.jpg & Subgroup 4 & - \\
\hline 4 & & 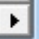 \\
\hline
\end{tabular}

Fig. 12 Program output for papaya classification. 
is, $50 \%-75 \%$ of yellow peel surface. Finally, images 011, 012, 013, 016 and 018 were classified as subgroup 5, which corresponded to ripe fruit, with $75 \%-100 \%$ of the surface of the peel yellowish.

In Table 3, it was possible to analyze the results obtained by the program (Fig. 12) and market subgroup for comparison. The program resulted in a correct evaluation in 16 images, representing $80 \%$ of correct classification. Meanwhile, it had 15\% of errors of classification above the real market and $5 \%$ below.

Using processing images to evaluate the colors of apples and their maturity, Zhou et al. [23] found a $R^{2}$ of 0.80 , a value close to the error of this experiment. Also, evaluating the colors in apples, Nicolai et al. [24] used hyperspectral NIR selecting the fruits with damages from the good ones.

Most of the errors found in the papaya classification were with classifications more mature than the reality. This error comes from a selection of the ROI from the center of the fruit, which tends to be yellower and the

Table 3 Subgroup analysis in response to program vs. market.

\begin{tabular}{lll}
\hline Image & Market subgroup & Algorithm subgroup \\
\hline Image 000 & 1 or 2 & 1 \\
Image 001 & 1 or 2 & 1 \\
Image 002 & 1 or 2 & 1 \\
Image 003 & 1 or 2 & 2 \\
Image 004 & 1 or 2 & 1 \\
Image 005 & 2 or 3 & 4 \\
Image 006 & 2 or 3 & 3 \\
Image 007 & 2 or 3 & 3 \\
Image 008 & 2 or 3 & 3 \\
Image 009 & 3 or 4 & 4 \\
Image 010 & 3 or 4 & 4 \\
Image 011 & 3 or 4 & 5 \\
Image 012 & 3 or 4 & 5 \\
Image 013 & 4 or 5 & 5 \\
Image 014 & 4 or 5 & 4 \\
Image 015 & 4 or 5 & 4 \\
Image 016 & 4 or 5 & 5 \\
Image 017 & 4 or 5 & 3 \\
Image 018 & 4 or 5 & 5 \\
Image 019 & 4 or 5 & 4 \\
\hline
\end{tabular}

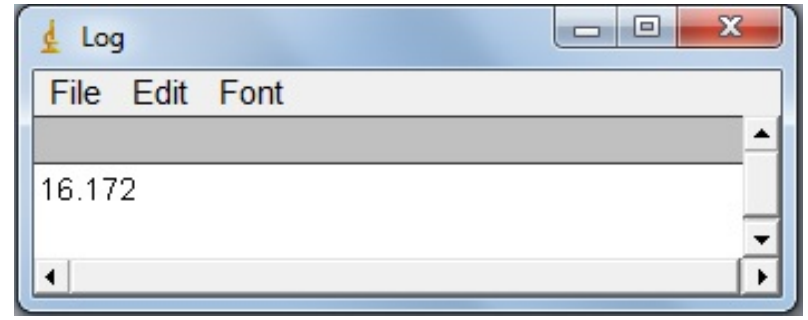

Fig. 13 Time to process twenty images (s).

Source: Compiled by the author.

Table 4 Gray level of the red channel of each image and classification of the fruits.

\begin{tabular}{lll}
\hline Name & Color classification & Mean \\
\hline Image 000.jpg & Subgrup 1 & 92.08 \\
Image 001.jpg & Subgrup 1 & 87.91 \\
Image 002.jpg & Subgrup 1 & 85.19 \\
Image 003.jpg & Subgrup 2 & 102.71 \\
Image 004.jpg & Subgrup 1 & 84.61 \\
Image 005.jpg & Subgrup 4 & 158.80 \\
Image 006.jpg & Subgrup 3 & 121.22 \\
Image 007.jpg & Subgrup 3 & 140.45 \\
Image 008.jpg & Subgrup 3 & 143.01 \\
Image 009.jpg & Subgrup 4 & 158.59 \\
Image 010.jpg & Subgrup 4 & 171.25 \\
Image 011.jpg & Subgrup 5 & 172.90 \\
Image 012.jpg & Subgrup 5 & 200.77 \\
Image 013.jpg & Subgrup 5 & 173.29 \\
Image 014.jpg & Subgrup 4 & 170.53 \\
Image 015.jpg & Subgrup 4 & 168.66 \\
Image 016.jpg & Subgrup 5 & 190.42 \\
Image 017.jpg & Subgrup 3 & 124.03 \\
Image 018.jpg & Subgrup 5 & 201.58 \\
Image 019.jpg & Subgrup 4 & 171.15 \\
\hline & &
\end{tabular}

extremes greener, so the area tends to represent a more mature fruit.

Fig. 13 showed the time to process twenty images in seconds that the program gives.

The program used a reasonable time to process all the images, of 16 seconds, so that was a good response. Also, the program classified most of the papayas in the right subgroup (Table 3), the exceptions were for the parts of the ROI selected different from most of the fruit. The experiment expected the error because no fruit is symmetrical or equal in all sides, 
Table 5 Input data for statistical analysis.

\begin{tabular}{lll}
\hline Subgroup & Repetition & Mean \\
\hline 1 & 1 & 92.08 \\
1 & 2 & 87.91 \\
1 & 3 & 85.19 \\
1 & 4 & 84.61 \\
3 & 1 & 121.22 \\
3 & 2 & 140.45 \\
3 & 3 & 143.01 \\
3 & 4 & 124.03 \\
4 & 1 & 158.80 \\
4 & 2 & 158.59 \\
4 & 3 & 171.25 \\
4 & 4 & 170.53 \\
5 & 1 & 172.90 \\
5 & 2 & 200.77 \\
5 & 3 & 173.29 \\
\hline
\end{tabular}

Table 6 Analysis of variance.

\begin{tabular}{llllll}
\hline SV & DF & SS & AS & Fc & Pr $>$ Fc \\
\hline Treatment & 3 & $21,539.266875$ & $7,179.755625$ & 73.380 & 0.0000 \\
Repetition & 3 & 234.831875 & 78.277292 & 0.800 & 0.5244 \\
Error & 9 & 880.585625 & 97.842847 & & \\
Total corrected & 15 & $22,654.684375$ & & & \\
CV $(\%)$ & 6.96 & & & 16 & \\
General mean & 142.1812500 & Number of observations: & & \\
\hline
\end{tabular}

SV: Source of variation; DF: degree of freedom; SS: sum of squares; AS: average squares; CV: coefficient of variation.

Table 7 Tukey's test results.

\begin{tabular}{lll}
\hline Treatments & Means & Test result \\
\hline 1 & 87.450 & A1 \\
3 & 132.150 & A2 \\
4 & 164.775 & A3 \\
5 & 184.350 & A3 \\
\hline
\end{tabular}

* Averages followed by the same letter and number do not differ by Tukey test at 5\% probability. MSD: minimum significant difference. A1, A2 and A3 are Tukey's test results.

MSD: 21.8437434968229; significance level: 0.05; harmonic mean of the number of repetitions $(r)$ : 4; standard error: 4.94577716901556.

since the image only captures one side and the program can result a different subgroup.

The data for statistical analysis were obtained from Table 4, where it selected four repetitions from each subgroup to integrate the data in Table 5.

The results of the statistical analysis can be seen in Tables 6 and 7.

In Tables 6 and 7, it can be seen that only subgroups 4 and 5 were not differentiated. The subgroups 1 and 3 were differentiated.

\section{Conclusions}

As a result of the experiment, through computer programs, different papaya formats were identified, varying from the "Formosa" to the "Solo" varieties in a correct manner. Also, papayas were classified into 
subgroups of maturity, according to the color of the skin with low error. This methodology can provide tools for fruit selection, in an objective, fast and cost-effective manner.

\section{Acknowledgements}

The authors would like to thank the School of Agricultural Engineering, as well as Dr. Sylvio Luís Honório and Dr. Silvestre Rodrigues for their assistance during the accomplishment of the experiments. Sincere thanks are also expressed to the National Council for Scientific and Technological Development (CNPq) for scholarship of the first author and Student Support Service-SAE/UNICAMP for scientific research scholarship of the last author.

\section{References}

[1] Cavalini, F. C., Jacomino, A. P., Lochoski, M. A., Kluge, R. A., and Ortega, E. M. M. 2006. "Maturity Indexes for 'Kumagai' and 'Paluma' Guavas.” Rev. Bras. Frutic. 28 (2): 176-9. doi:10.1590/S0100-29452006000200005.

[2] Trevisan, R., Treptow, R. O., Gonçalves, E. D., Antunes, L. E. C., and Herter, F. G. 2006. "Attributes of Quality Considered by the Consumer of Pelotas/RS, in the Purchase of Peach in Natura." Current Agricultural Science and Technology (CAST) 12: 371-4. (in Portuguese)

[3] Chitarra, M. I. F., and Chitarra, A. B. 2005. Post-harvesting of Fruits and Vegetables: Physiology and Handling. Lavras: UFLA. (in Portuguese)

[4] Balbino, J. M. S. 1997. Effects of Hot Water, Cold Storage and Ethephon on Papaya (Carica papaya L.) Postharvest Quality. University of Viçosa. (in Portuguese)

[5] Dongowski, G. 1973. "The Biochemistry of Fruits and Their Products. Herausgegeben von A. C. Hulme. Bd. II, XVIII und 788 Seiten. Academic Press, London und New York 1971. Preis: 12,00 £, 35,00 \$.” Food Nahr. 17 (6): 687-8. doi:10.1002/food.19730170618.

[6] Reinhardt, D. H., Medina, V. M., Caldas, R. C., Da Cunha, G. A. P., and Estevam, R. F. H. 2004. "Quality Gradients in 'Pérola' Pineapple Depending on the Size and Stage of Fruit Maturation.” Brazilian Journal of Fruit Growing 26: 544-6. doi:10.1590/S0100-294520040003 00041. (in Portuguese)

[7] Bron, I. U., and Jacomino, A. P. 2006. "Ripening and Quality of 'Golden' Papaya Fruit Harvested at Different Maturity Stages.” Braz. J. Plant Physiol. 18 (3): 389-96.
doi:10.1590/S1677-04202006000300005.

[8] Barchi, G. L., Berardinelli, A., Guarnieri, A., Ragni, L., and Fila, C. T. 2002. "PH-Postharvest Technology: Damage to Loquats by Vibration-Simulating Intra-state Transport.” Biosyst. Eng. 82 (3): 305-12. doi:10.1006/bioe.2002.0067.

[9] Tokushisa, D., Dias, D. C. F. S., Alvarenga, E. M., Dias, L. A. S., and Marin, S. L. 2008. "Time of Fruit Harvest and Occurrence of Dormancy in Papaya Seeds (Carica papaya L.)" Journal of Seed Science 30: 75-80. (in Portuguese)

[10] 2013. Papaya: The Producer Asks, Embrapa Responds, 2nd ed.. Brasilia, DF: Embrapa. (in Portuguese)

[11] Fioravanço, J. C., Paiva, M. C., De Carvalho, R. I. N., and Manica, I. 1994. "Characteristics of Formosa Papaya Commercialized in Porto Alegre from October/1991 to June/1992.” Ciênc. Rural 24 (3): 519-22. doi:10.1590/S0103-84781994000300012. (in Portuguese)

[12] Fagundes, G. R., and Yamanishi, O. K. 2001. "Physical and Chemical Characteristics of 'Solo' Mammalian Fruit Commercialized in Four Establishments of Brasília, DF.” Brazilian Journal of Fruit Growing 23: 541-5. doi:10.1590/S0100-29452001000300018. (in Portuguese)

[13] Internationale Beleuchtungskommission. 2004. Colorimetry, 3rd ed.. Vienna: CIE, Central Bureau.

[14] Gates, D. M. 2011. Biophysical Ecology. New York: Springer. ISBN 978-1-4612-6024-0.

[15] Krause, G. H., and Weis, E. 1991. "Chlorophyll Fluorescence and Photosynthesis: The Basics.” Annu. Rev. Plant Physiol. Plant Mol. Biol. 42: 313-49. doi:10.1146/annurev.pp.42.060191.001525.

[16] Von Willert, D. J., Matyssek, R., and Herppich, W. 1995. Experimental Plant Ecology, Fundamentals and Applications. Stuttgart: Georg-Thieme-Verlag, 344.

[17] Serrano, M., Guillén, F., Martínez-Romero, D., Castillo, S., and Valero, D. 2005. "Chemical Constituents and Antioxidant Activity of Sweet Cherry at Different Ripening Stages.” J. Agric. Food Chem. 53 (7): 2741-5. doi:10.1021/jf0479160.

[18] Whetzel, N. 2015. "Measuring Color Using Hunter L, a, b versus CIE $1976 \quad \mathrm{~L}^{*} \mathrm{a}^{*} \mathrm{~b}^{*}$-AN-1005b." https://support.hunterlab.com/hc/en-us/articles/20413782 5-Measuring-Color-using-Hunter-L-a-b-versus-CIE-1976 -L-a-b-AN-1005b.

[19] Pathare, P. B., Opara, U. L., and Al-Said, F. A. J. 2013. "Colour Measurement and Analysis in Fresh and Processed Foods: A Review.” Food Bioprocess Technol. 6 (1): 36-60. doi:10.1007/s11947-012-0867-9.

[20] CEAGESP. 2004. Papaya Classification Standards. www.ceagesp.gov.br/wp-content/uploads/2015/07/mama o.pdf. (in Portuguese)

[21] Perez, J. M. M., and Pascau, J. 2013. Image Processing 
with ImageJ. Birmingham, UK: Packt Publishing.

[22] Omid, M., Khojastehnazhand, M., and Tabatabaeefar, A. 2010. "Estimating Volume and Mass of Citrus Fruits by Image Processing Technique.” J. Food Eng. 100 (2): 315-21. doi:10.1016/j.jfoodeng.2010.04.015.

[23] Zhou, R., Damerow, L., Sun, Y., and Blanke, M. M. 2012. “Using Colour Features of cv. 'Gala' Apple Fruits in an
Orchard in Image Processing to Predict Yield.” Precis. Agric. 13 (5): 568-80. doi:10.1007/s11119-012-9269-2.

[24] Nicolaï, B. M., Lötze, E., Peirs, A., Scheerlinck, N., and Theron, K. I. 2006. "Non-destructive Measurement of Bitter Pit in Apple Fruit Using NIR Hyperspectral Imaging.” Postharvest Biol. Technol. 40: 1-6. doi:10.1016/j.postharvbio.2005.12.006. 